\title{
Improvement In Colorectal Cancer Outcomes Over Time is Limited To Patients With Left-Sided Disease
}

Holger Rumpold ( $\square$ holger.rumpold@ordensklinikum.at)

Gastrointestinal Cancer Center, Ordensklinikum Linz https://orcid.org/0000-0002-4118-0111

Monika Hackl

National Cancer Registry, Statistics Austria

Andreas Petzer

Ordensklinikum Linz

Dominik Wolf

Medical University Innsbruck

\section{Research Article}

Keywords: colorectal cancer, mortality, incidence, outcome, primary tumor localization

Posted Date: October 26th, 2021

DOI: https://doi.org/10.21203/rs.3.rs-1015558/v1

License: (9) This work is licensed under a Creative Commons Attribution 4.0 International License.

Read Full License

Version of Record: A version of this preprint was published at Journal of Cancer Research and Clinical Oncology on January 3rd, 2022. See the published version at https://doi.org/10.1007/s00432-021-038680 . 


\section{Abstract}

Purpose: Incidence and mortality of colorectal cancer (CRC) declined over the last decades. However, survival depends on the primary tumor location. It is unknown if all progress in outcomes vary depending on left-sided (LCRC) versus right sided (RCC) colorectal cancer. We compare incidence and mortality rates over time according to the primary tumor location.

Methods: Data from the Austrian National Cancer Registry spanning from 1983 to 2018 were used to calculate annual incidence and mortality rates and survival stratified by primary tumor localization and stage. Joinpoint regression with linear regression models were used on different subgroups to identify significant changes of incidence- and mortality slopes.

Results: A total of 168,260 (incidence-data set) and 87,355 cases (mortality data-set) were identified. Survival of disseminated RCC was worse compared to LCRC (HR 1.14; CI 1.106-1.169). Total and LCRC incidence- and mortality-rates declined steadily over time, whereas the rates of RCC did not. Incidence of disseminated RCC declined significantly less (slope $-0.07 ; \mathrm{Cl}-0.086 ;-0.055)$ than in LCRC (slope $-0.159 ; \mathrm{Cl}$ $-0.183 ;-0.136)$; mortality rate of RCC was unchanged over time. Incidence and mortality of localized RCC remained unchanged over time, whereas both rates declined independently of stage in LCRC.

Conclusion: Colorectal cancer outcomes during the last 35 years have preferentially improved in LCRC but not in RCC, indicating that the progress made is limited to LCRC. It is necessary to define RCC as a distinct form of CRC and to focus on specific strategies for its early detection and treatment.

\section{Introduction}

Incidence and mortality rate estimates of cancer are valuable tools to evaluate the effect of innovations in management of these diseases (Carioli et al. 2021). Colorectal cancer (CRC) is the third most common cancer worldwide (Ferlay et al. 2015). Fortunately, over the last centuries the incidence and mortality of CRC show a consistent decline (Malvezzi et al. 2018). This positive impact over time is based on more than one factor. For example, CRC incidence and mortality tend to response faster and more sensitive than other cancer types to lifestyle and dietary changes, which has been suggested by migrant studies (Kolonel and Wilkens 2009). Such dietary and lifestyle adaptions have been occurring during the last centuries, leading to a convergence of CRC mortality in the European Union (Fernández et al. 2005; Bosetti et al. 2011). Besides that, due to slow progression of precancerous lesions and the high cure rate of early stages of CRC, screening strategies by endoscopy and other methods for prevention and early detection of are very effective (Issa and NouredDine 2017). Finally, progress in treatment of CRC in both localized (eCRC) and metastatic ( $\mathrm{mCRC}$ ) stages have significantly contributed to the decrease in mortality. This clinical progress is exemplified by the introduction of doublet chemotherapy in the adjuvant setting in eCRC based on data from several trials (Sargent et al. 2011). In mCRC the addition of oxaliplatin or irinotecan to 5 -fluouracil as backbone as well as the introduction of targeting the epidermal growth factor receptor (EGFR) and angiogenesis in systemic treatment concepts has led to steadily 
increasing survival even in the metastatic setting (Bokemeyer et al. 2012; Douillard et al. 2014; Glimelius et al. 2021). This progress in disseminated disease is further supported by the introduction of multimodal treatments (Heervä et al. 2018). However, CRC is not a homogenous disease. In particular, tumors arising from different anatomic regions of the colorectum are clinically and molecularly different (Bufill 1990; Carethers 2011; Yamauchi et al. 2012a, b; Missiaglia et al. 2014). It is hypothesized, that differences in the luminal content, e.g. the bacterial flora, as well as ontogenesis with left-sided colorectal cancers (LCRC) deriving from the hindgut and right-sided colon cancer (RCC) deriving from the midgut are at least part reasons for theses side specific differences (lacopetta 2002; LaPointe et al. 2008; Holch et al. 2017b; Boeckx et al. 2018) (lacopetta 2002; LaPointe et al. 2008; Holch et al. 2017a). The most appropriate embryonic demarcation line to delineate distal LCRC from proximal RCC is found in the distal third of the colon transversum. This region is difficult to define in a clinical setting. As an approximation the splenic flexure is used to separate LCRC from RCC in most clinical reports (Modest et al. 2014; Von Einem et al. 2014; Loupakis et al. 2015; Tejpar et al. 2017a; Sunakawa et al. 2017). Only few reports solve this issue by excluding cases with the primary in the colon transversum (Venook et al. 2017). On the other hand, some authors exclude rectal cancers from LCRC (Meguid et al. 2008). However, as similar outcomes in rectal cancer and left sided colon cancer has been shown, rectal cancer is assigned to the LCRC group (Price et al. 2015).

Clinically, RCC and LCRC differ substantially. LCRC is more common and more frequently associated with chromosomal instability and a gene expression profiles suggesting the activation of the epithelia growth factor receptor (EGFR) pathway. RCC is more frequently associated with mircrosatellite instability, is usually diagnosed at higher stages and shows more often driver mutations of RAS, BRAF and PIK3CA genes (Bendardaf et al. 2008; Missiaglia et al. 2014; Guinney et al. 2015). These differences translate in a much worse clinical outcomes for RCC compared to LCRC, especially in disseminated disease (Benedix et al. 2010; Weiss et al. 2011; Modest et al. 2014; Von Einem et al. 2014; Missiaglia et al. 2014; Loupakis et al. 2015; Zhang et al. 2015; Guinney et al. 2015; Krauth et al. 2018). However, side-specific differences have not been implicated in clinical trials, which makes it currently difficult to consider sidedness for treatment decisions in clinical practice. In addition to a poorer prognosis of patients with RCC, screening colposcopy seems to prevent LCRC more efficiently than RCC, which might be based on side-specific appearance of precancerous lesion (flat-serrated in the right side, polypous on the left side), in combination with technical difficulties associated with completing colonoscopy to the very proximal regions (Brenner et al. 2014).

Less early detection rates and worse survival raise the question as to whether improvements in clinical outcomes of CRC over time are similar for LCRC and RCC. The aim of this study was to investigate stage specific overall survival, incidence- and mortality-rates of LCRC and RCC in the Austrian population from 1983 to 2018.

\section{Material And Methods}

\section{Sample population}


Data for incidence and mortality of colon cancer from 1983 to 2018 were exported from the Austrian National Cancer Registry (ANCR) and the und the Austrian Causes of Death Statistics, extraction code: DBABZUG_20201217101752454. End of follow up was Dec 31st 2019. Variables contained year of diagnosis, diagnosis and anatomical location coded according to the International Classification of Disease, $10^{\text {th }}$ revision (ICD-10) codes, stage at diagnosis (local, regional, disseminated, death certificate only [DCO] or unknown), gender, survival time in days, year of death and cause of death based on the ICD10 .

\section{Primary tumor location (PTL)}

LCRC was defined based on the ICD-10 codes as cancer arising from the rectum (C20), rectosigmoid (C19), sigma (C18.7), colon descendens (C18.6), and the splenic flexure (C18.5);

RCC was defined as cancer arising from the colon transversum (C18.4), hepatic flexure (C18.3), colon ascendens (C18.2), coecum (C18.0) and the appendix (C18.1). The codes 'Others, not specified' (C18.8 and C18.9) were excluded from the analysis. Also patients coded for 'in situ' disease (D01) were excluded.

\section{Statistical analysis}

Overall survival (OS; Kaplan-Meier method) and Hazard Ratio (HR) were calculated to describe the difference in survival between LCRC and RCC in metastasized and localized cases. In the statistical models, the values were normalized to population data and rates per 100,000 residents. Joinpoint regression with linear regression models were used on different subgroups to find the inflection point (joinpoint year) of slope changes (Muggeo 2003). Assumptions of linear regression models such as normality of residuals, no outliers or influential cases, Homoscedasticity, linearity and independence of residuals were verified using graphical methods (Q-Q-plot, scatterplots) and the Durbin Watson value. One outlier (mortality data-set, LCRC, year of diagnosis 1983) was deleted.

The results of the joinpoint analyses with linear regression models of data after the joinpoint year were reported with model fit, model coefficients and p-values. Additionally the slopes were compared via $90 \%$ confidence intervals (Cls) with no overlap of the $90 \%$ Cls to show significantly different slopes at a significance level of $5 \%$ (Goldstein and Healy 1995).

The software $\mathrm{R}$ version 4.0.3 was used for all statistical data analyses (https://www-R-project.org). The package segmented in $\mathrm{R}$ was used for joinpoint regression. A level of significance of $5 \%$ was used.

\section{Results}

\section{Population and distribution of PTL}

A total of 168,260 incidence cases diagnosed with colon cancer were identified in the ANCR from 1983 to 2018. Data on the PTL was available $81.2 \%$ of the cases. Of these, $73.4 \%$ were LCRC and $26.6 \%$ were 
RCC; $59.3 \%$ were located in the colon and $40.7 \%$ in the rectum. Information on stage distribution at diagnosis was available in $79.7 \%$ of the cases; $22.6 \%$ were diagnosed with metastatic disease. A total of 87,355 cases died from colon cancer during the study period. Data for PTL in this mortality dataset was available for $53.1 \%$ of the cases. Of these $86.4 \%$ had LCRC and $13.6 \%$ RCC; $40 \%$ had colon cancer and $60 \%$ rectum cancer at death. Information on stage distribution at diagnosis was available in $69.5 \%$ of the cases; $39.8 \%$ of the cases had metastatic disease (Table 1 ).

\section{OS according to stage and PTL}

PTL was associated with OS in the whole sample. LCRC showed longer OS than RCC (HR 1.14; Cl 1.106; 1.17; Figure 1A) in metastatic disease. This difference was not evident in cases without metastases at diagnosis. Survival curves in this group were crossing, which not allows calculation of a HR and making a reliable interpretation difficult. However, it suggests no impact on survival (Figure 1B).

\section{Incidence and mortality according to PTL}

Jointpoint regression of the incidence showed a significant decrease since 2000 for LCRC and since 1999 for RCC. A stronger decline was observed in incidence for LCRC (slope $-0.739 ; 90 \% \mathrm{Cl}-0.799 ;-0.678$ ) than for RCC (slope $-0.124 ; 90 \% \mathrm{Cl}-0.156 ;-0.092$ ). The missing overlap of the $\mathrm{Cl}$ values of the slopes suggest a significant difference (Figure 2A). Similar results were obtained for mortality. The jointpoint for both incidence and mortality was 1988. Comparison of the respective slopes of the linear regression showed a stronger decrease in mortality for LCRC (slope $-0.169 ; 90 \% \mathrm{Cl}$ for slope $-0.185 ;-0.154$ ) than for RCC (slope $0.01 ; 90 \% \mathrm{Cl}$ for slope $0.003 ;-0.016$ ). Again, the missing overlap of the $\mathrm{Cl}$ values of the slopes suggest a significant difference for mortality over time (Figure 2B).

\section{Incidence and mortality according to PTL and stage}

The incidence of LCRC showed a steady decline over time in both non-disseminated (slope $-0.53 ; 90 \% \mathrm{Cl}$ $-0.589 ;-0.471$ ) and disseminated disease (slope $-0.159 ; 90 \% \mathrm{Cl}-0.183 ;-0.136)$. In contrast, the incidencerates of RCC declined less in cases with disseminated disease (slope $-0.07 ; 90 \% \mathrm{Cl}-0.086 ;-0.055$ ) and remained almost unchanged in non-disseminated cases (slope $-0.062 ; 90 \% \mathrm{Cl}-0.088 ;-0.036)$. Nonoverlapping $\mathrm{Cl}$ ranges suggest a significant difference of the slopes (Figure $3 \mathrm{~A}$ and $\mathrm{C}$ ).

Similar findings were observed for mortality over time. Mortality of LCRC showed a strong decrease in both non-disseminated (slope $-0.116 ; 90 \% \mathrm{Cl}-0.126 ;-0.105$ ) and disseminated disease (slope $-0.078 ; 90 \%$ $\mathrm{Cl}-0.103 ;-0.054)$. Almost no change in mortality over time was observed for RCC in both non-

disseminated (slope $0.005 ; 90 \% \mathrm{Cl} 0.001 ; 0.009$ ) and disseminated disease (slope $-0.008 ;-0.017 ; 0$ ). Nonoverlapping $\mathrm{Cl}$ ranges suggest a significant difference of the slopes (Figure $3 \mathrm{~B}$ and $\mathrm{D}$ ).

\section{Discussion}

Our analysis shows, to our knowledge for the first time that both the incidence and mortality rates over the last 35 years have developed differently for LCRC and RCC. While the rates of LCRC have been 
steadily declining over time, the rates for RCC remained largely unchanged. The lack of progress in outcome of RCC might be due to several factors. Several trials since 1992 suggested a major protective effect of colonoscopy and sigmoidoscopy against colorectal cancer by detecting and removing precancerous lesions, which resulted in an increased screening activity in many countries (Selby et al. 1992; Newcomb et al. 1992; Winawer et al. 1993; Stock et al. 2011; Shapiro et al. 2012; Issa and NouredDine 2017). This might be one of the major reasons for the decline of incidence rates since then. However, the detection rate of proximal neoplasms is significantly lower than the detection rate of distal neoplasms (Bressler et al. 2004, 2007; Singh et al. 2006; Brenner et al. 2014). Another reason might be found in well-known differences in the appearance of premalignant neoplasms, including flat lesions in the proximal colon, which are rather overseen compared to the typical polypous lesions in the left colon (lacopetta 2002; Nawa et al. 2008; Arain et al. 2010). This might be reasonable, if sigmoidoscopy, inspecting parts of the left colorectum only, were the predominant method used in these publications. However, the same difference in detection rates is found if total colonoscopy is used (Baxter et al. 2009; Mulder et al. 2010; Ostenfeld et al. 2013). It has even been shown, that the reduction in CRC-related mortality in a colonoscopy-screened population seems to be restricted to LCRC without affecting mortality from RCC (Singh et al. 2010). This observation is in line with our findings that the mortality rate for RCC remains unchanged over time, while the same rate for LCRC is constantly declining over the last centuries.

Incidence-rates according to stage at diagnosis showed that the occurrence of disseminated RCCs have been declining to some extent. Here again the effect is much more pronounced for LCRC and nonoverlapping $\mathrm{Cl}$-ranges of the two slopes suggest a significant difference. This difference in incidencerates was not found for localized disease, implying a stage-migration from disseminated disease to locoregional disease that potentially is gained by screening also for RCC. One could hypothesize that the main effect of screening is earlier detection, but not preventing RCC. However, the mortality rate for disseminated RCC has not changed to the same extent as the respective incidence rate. This might reflect the reduced benefit that RCC gains from oncological treatment based on the biological differences between RCC and LCRC, especially, if the RAS-mutation status is considered in oncological treatment decisions (Benedix et al. 2010; Weiss et al. 2011; Modest et al. 2014; Von Einem et al. 2014; Missiaglia et al. 2014; Loupakis et al. 2015; Zhang et al. 2015; Guinney et al. 2015; Venook et al. 2016; Arnold et al. 2017). Both less effective screening and less effective treatment aspects contribute to an unfavorable development in mortality of RCC, especially in disseminated stages.

In published observations reporting on differences in the clinical outcome in LCRC and RCC the relative 5year survival rates are applied for comparing oncological outcome between distinct time intervals (Brouwer et al. 2018; Dulskas et al. 2020). The risk of a lead-time bias in such approaches is problematic, especially in CRC, which is a screening sensitive disease. This potential bias in that context has been addressed by several authors (Welch et al. 2000; Gigerenzer and Wegwarth 2013). Comparing time intervals before and after the millennium is particularly problematic, as screening was introduced around the turn of the millennium leading to earlier diagnosis of CRC, which implies the risk of prolonged overall survival times. This might explain to some extent why not all of the published results are 
conclusive. For example, in one study the relative increase in clinical benefit from 1998-2008 compared to 2008-2012 was $11 \%$ less for LCRC than for RCC (Dulskas et al. 2020). This length bias can be avoided by using mortality rates rather than survival times or survival rates (Welch et al. 2000; Gigerenzer and Wegwarth 2013).

Several factors underline the reliability of our results. In addition to the high numbers of cases included, the information on the location of primary tumor was available in $81.2 \%$ of the cases for calculating incidence rates. The distribution of LCRC and RCC within this population can be well compared to the literature, as it reflects PTL at diagnosis. We found $73.3 \%$ LCRC and $26.6 \%$ RCC, which is a well comparable distribution also found by others and supports, that our dataset is not biased by documentation issues (Benedix et al. 2010; Holch et al. 2017b). Furthermore, our data on $22.6 \%$ disseminated disease at time of diagnosis align with those reported from a dataset of the Netherland Cancer Registry (Brouwer et al. 2018).

Variations in the prognostic impact of PTL on survival were also found in our study. This stage-specific difference is well known and broadly reported and the accordance of our results with the literature indicates the validity of our dataset (Weiss et al. 2011; Tejpar et al. 2017b). Information on PTL at time of death derived from death certificates was available for half of the cases; due to the lack of reports describing the distribution of PTL at this time point, it is difficult to compare these numbers with the literature.

This study provides a nationally representative perspective in trends of colon cancer outcomes. We report an evolving disparity in outcomes for patients suffering from RCC compared to oncological progress in patients with LCRC in both incidence and mortality. These findings underline the necessity to consider RCC as a distinct disease, which requires more efficient prevention-, treatment- and specific future research strategies.

\section{Declarations}

Acknowledgement: none

Declaration of Interest statement: no conflicts declared by the authors

Funding: no funding for the project

\section{References}

1. Arain MA, Sawhney M, Sheikh S, et al (2010) CIMP status of interval colon cancers: Another piece to the puzzle. Am J Gastroenterol 105:1189-1195. https://doi.org/10.1038/ajg.2009.699

2. Arnold D, Lueza B, Douillard JY, et al (2017) Prognostic and predictive value of primary tumour side in patients with RAS wild-type metastatic colorectal cancer treated with chemotherapy and EGFR 
directed antibodies in six randomized trials. Ann Oncol 28:1713-1729.

https://doi.org/10.1093/annonc/mdx175

3. Baxter NN, Goldwasser MA, Paszat LF, et al (2009) Association of colonoscopy and death from colorectal cancer. Ann Intern Med 150:1-8. https://doi.org/10.7326/0003-4819-150-1-20090106000306

4. Bendardaf R, Buhmeida A, Hilska M, et al (2008) VEGF-1 expression in colorectal cancer is associated with disease localization, stage, and long-term disease-specific survival. In: Anticancer Res. https://pubmed.ncbi.nlm.nih.gov/19192642/. Accessed 22 Jun 2021

5. Benedix F, Kube R, Meyer F, et al (2010) Comparison of 17,641 patients with right- and left-sided colon cancer: Differences in epidemiology, perioperative course, histology, and survival. Dis Colon Rectum 53:57-64. https://doi.org/10.1007/DCR.0b013e3181c703a4

6. Boeckx N, Janssens K, Van Camp G, et al (2018) The predictive value of primary tumor location in patients with metastatic colorectal cancer: A systematic review. Crit. Rev. Oncol. Hematol. 121:1-10

7. Bokemeyer C, Cutsem E Van, Rougier P, et al (2012) Addition of cetuximab to chemotherapy as firstline treatment for KRAS wild-type metastatic colorectal cancer: Pooled analysis of the CRYSTAL and OPUS randomised clinical trials. Eur J Cancer 48:1466-1475. https://doi.org/10.1016/j.ejca.2012.02.057

8. Bosetti C, Bertuccio P, Chatenoud L, et al (2011) Trends in mortality from urologic cancers in Europe, 1970-2008. Eur Urol 60:1-15. https://doi.org/10.1016/j.eururo.2011.03.047

9. Brenner H, Stock C, Hoffmeister M (2014) Effect of screening sigmoidoscopy and screening colonoscopy on colorectal cancer incidence and mortality: Systematic review and meta-analysis of randomised controlled trials and observational studies. BMJ 348:. https://doi.org/10.1136/bmj.g2467

10. Bressler B, Paszat LF, Chen Z, et al (2007) Rates of New or Missed Colorectal Cancers After Colonoscopy and Their Risk Factors: A Population-Based Analysis. Gastroenterology 132:96-102. https://doi.org/10.1053/j.gastro.2006.10.027

11. Bressler B, Paszat LF, Vinden C, et al (2004) Colonoscopic miss rates for right-sided colon cancer: A population-based analysis. Gastroenterology 127:452-456.

https://doi.org/10.1053/j.gastro.2004.05.032

12. Brouwer NPM, Bos ACRK, Lemmens VEPP, et al (2018) An overview of 25 years of incidence, treatment and outcome of colorectal cancer patients. Int J Cancer 143:2758-2766. https://doi.org/10.1002/ijc.31785

13. Bufill JA (1990) Colorectal cancer: Evidence for distinct genetic categories based on proximal or distal tumor location. Ann. Intern. Med. 113:779-788

14. Carethers JM (2011) One colon lumen but two organs. Gastroenterology 141:411-412

15. Carioli G, Malvezzi M, Bertuccio P, et al (2021) European cancer mortality predictions for the year 2021 with focus on pancreatic and female lung cancer. Ann Oncol 32:478-487. https://doi.org/10.1016/j.annonc.2021.01.006 
16. Douillard JY, Siena S, Cassidy J, et al (2014) Final results from PRIME: Randomized phase III study of panitumumab with FOLFOX4 for first-line treatment of metastatic colorectal cancer. Ann Oncol 25:1346-1355. https://doi.org/10.1093/annonc/mdu141

17. Dulskas A, Gaizauskas V, Kildusiene I, et al (2020) Improvement of Survival over Time for Colorectal Cancer Patients: A Population-Based Study. J Clin Med 9:4038. https://doi.org/10.3390/jcm9124038

18. Ferlay J, Soerjomataram I, Dikshit R, et al (2015) Cancer incidence and mortality worldwide: Sources, methods and major patterns in GLOBOCAN 2012. Int J Cancer 136:E359-E386. https://doi.org/10.1002/ijc.29210

19. Fernández E, Vecchia C La, González JR, et al (2005) Converging patterns of colorectal cancer mortality in Europe. Eur J Cancer 41:430-437. https://doi.org/10.1016/j.ejca.2004.11.014

20. Gigerenzer G, Wegwarth $O$ (2013) Five year survival rates can mislead. BMJ 346

21. Glimelius B, Stintzing S, Marshall J, et al (2021) Metastatic colorectal cancer: Advances in the folatefluoropyrimidine chemotherapy backbone. Cancer Treat Rev 98:102218. https://doi.org/10.1016/j.ctrv.2021.102218

22. Goldstein H, Healy MJR (1995) No Title. J R Stat Soc Ser A (Statistics Soc 158:175-177

23. Guinney J, Dienstmann R, Wang X, et al (2015) The consensus molecular subtypes of colorectal cancer. Nat Med 21:1350-1356. https://doi.org/10.1038/nm.3967

24. Heervä E, Lavonius M, Jaakkola P, et al (2018) Overall Survival and Metastasis Resections in Patients with Metastatic Colorectal Cancer Using Electronic Medical Records. J Gastrointest Cancer 49:245251. https://doi.org/10.1007/s12029-017-9927-8

25. Holch JW, Demmer M, Lamersdorf C, et al (2017a) Pattern and Dynamics of Distant Metastases in Metastatic Colorectal Cancer. Visc Med 33:70-75. https://doi.org/10.1159/000454687

26. Holch JW, Ricard I, Stintzing S, et al (2017b) The relevance of primary tumour location in patients with metastatic colorectal cancer: A meta-analysis of first-line clinical trials. Eur J Cancer 70:87-98. https://doi.org/10.1016/j.ejca.2016.10.007

27. lacopetta B (2002) Are there two sides to colorectal cancer? Int. J. Cancer 101:403-408

28. Issa IA, NouredDine M (2017) Colorectal cancer screening: An updated review of the available options. World J. Gastroenterol. 23:5086-5096

29. Kolonel LN, Wilkens LR (2009) Migrant Studies. In: Schottenfeld D, Fraumeni JF (eds) Cancer Epidemiology and Prevention, 3rd edn. Oxford University Press, New York, NY, pp 189-201

30. Krauth MT, Burgstaller S, Buxhofer-Ausch V, et al (2018) Ruxolitinib therapy for myelofibrosis in Austria: Consensus on therapy management. Wien Klin Wochenschr 130:495-504. https://doi.org/10.1007/s00508-018-1365-5

31. LaPointe LC, Dunne R, Brown GS, et al (2008) Map of differential transcript expression in the normal human large intestine. Physiol Genomics 33:50-64. https://doi.org/10.1152/physiolgenomics.00185.2006 
32. Loupakis F, Yang D, Yau L, et al (2015) Primary tumor location as a prognostic factor in metastatic colorectal cancer. J Natl Cancer Inst 107:. https://doi.org/10.1093/jnci/dju427

33. Malvezzi M, Carioli G, Bertuccio P, et al (2018) European cancer mortality predictions for the year 2018 with focus on colorectal cancer. Ann Oncol 29:1016-1022. https://doi.org/10.1093/annonc/mdy033

34. Meguid RA, Slidell MB, Wolfgang CL, et al (2008) Is there a difference in survival between rightversus left-sided colon cancers? Ann Surg Oncol 15:2388-2394. https://doi.org/10.1245/s10434008-0015-y

35. Missiaglia E, Jacobs B, D'Ario G, et al (2014) Distal and proximal colon cancers differ in terms of molecular, pathological, and clinical features. Ann Oncol 25:1995-2001. https://doi.org/10.1093/annonc/mdu275

36. Modest DP, Schulz C, Von Weikersthal LF, et al (2014) Outcome of patients with metastatic colorectal cancer depends on the primary tumor site (midgut vs. hindgut): Analysis of the FIRE1-trial (FuFIRI or mIROX as first-line treatment). Anticancer Drugs 25:212-218. https://doi.org/10.1097/CAD.0000000000000041

37. Muggeo VMR (2003) Estimating regression models with unknown break-points. Stat Med 22:30553071. https://doi.org/10.1002/sim.1545

38. Mulder SA, Van Soest EM, Dieleman JP, et al (2010) Exposure to colorectal examinations before a colorectal cancer diagnosis: A case-control study. Eur J Gastroenterol Hepatol 22:437-443. https://doi.org/10.1097/MEG.0b013e328333fc6a

39. Nawa T, Kato J, Kawamoto $\mathrm{H}$, et al (2008) Differences between right- and left-sided colon cancer in patient characteristics, cancer morphology and histology. J Gastroenterol Hepatol 23:418-423. https://doi.org/10.1111/j.1440-1746.2007.04923.x

40. Newcomb PA, Norfleet RG, Storer BE, et al (1992) Screening sigmoidoscopy and colorectal cancer mortality. J Natl Cancer Inst 84:1572-1575. https://doi.org/10.1093/jnci/84.20.1572

41. Ostenfeld EB, Nørgaard M, Thomsen RW, et al (2013) Comorbidity and survival of Danish patients with colon and rectal cancer from 2000-2011: A population-based cohort study. Clin Epidemiol 5:6574. https://doi.org/10.2147/CLEP.S47154

42. Price TJ, Beeke C, Ullah S, et al (2015) Does the primary site of colorectal cancer impact outcomes for patients with metastatic disease? Cancer 121:830-835. https://doi.org/10.1002/cncr.29129

43. Sargent D, Shi Q, Yothers G, et al (2011) Two or three year disease-free survival (DFS) as a primary end-point in stage III adjuvant colon cancer trials with fluoropyrimidines with or without oxaliplatin or irinotecan: Data from 12,676 patients from MOSAIC, X-ACT, PETACC-3, C-06, C-07 and C89803. Eur J Cancer 47:990-996. https://doi.org/10.1016/j.ejca.2010.12.015

44. Selby J V., Friedman GD, Quesenberry CP, Weiss NS (1992) A Case-Control Study of Screening Sigmoidoscopy and Mortality from Colorectal Cancer. N Engl J Med 326:653-657. https://doi.org/10.1056/nejm199203053261001 
45. Shapiro JA, Klabunde CN, Thompson TD, et al (2012) Patterns of colorectal cancer test use, including CT colonography, in the 2010 National Health Interview Survey. Cancer Epidemiol Biomarkers Prev 21:895-904. https://doi.org/10.1158/1055-9965.EPI-12-0192

46. Singh $H$, Nugent Z, Demers AA, et al (2010) The reduction in colorectal cancer mortality after colonoscopy varies by site of the cancer. Gastroenterology 139:1128-1137. https://doi.org/10.1053/j.gastro.2010.06.052

47. Singh $H$, Turner $D$, Xue $L$, et al (2006) Risk of developing colorectal cancer following a negative colonoscopy examination: Evidence for a 10-year interval between colonoscopies. J Am Med Assoc 295:2366-2373. https://doi.org/10.1001/jama.295.20.2366

48. Stock C, Ihle P, Schubert I, Brenner H (2011) Colonoscopy and fecal occult blood test use in Germany: Results from a large insurance-based cohort. Endoscopy 43:771-779. https://doi.org/10.1055/s0030-1256504

49. Sunakawa Y, Ichikawa W, Tsuji A, et al (2017) Prognostic Impact of Primary Tumor Location on Clinical Outcomes of Metastatic Colorectal Cancer Treated With Cetuximab Plus Oxaliplatin-Based Chemotherapy: A Subgroup Analysis of the JACCRO CC-05/06 Trials. Clin Colorectal Cancer 16:e171-e180. https://doi.org/10.1016/j.clcc.2016.09.010

50. Tejpar S, Stintzing S, Ciardiello F, et al (2017a) Prognostic and predictive relevance of primary tumor location in patients with ras wild-type metastatic colorectal cancer retrospective analyses of the CRYSTAL and FIRE-3 trials. In: JAMA Oncology. American Medical Association, pp 194-201

51. Tejpar S, Stintzing S, Ciardiello F, et al (2017b) Prognostic and predictive relevance of primary tumor location in patients with ras wild-type metastatic colorectal cancer retrospective analyses of the CRYSTAL and FIRE-3 trials. JAMA Oncol 3:194-201. https://doi.org/10.1001/jamaoncol.2016.3797

52. Venook AP, Niedzwiecki D, Innocenti F, et al (2016) Impact of primary $\left(1^{\circ}\right)$ tumor location on overall survival (OS) and progression-free survival (PFS) in patients (pts) with metastatic colorectal cancer (mCRC): Analysis of CALGB/SWOG 80405 (Alliance). J Clin Oncol 34:3504-3504. https://doi.org/10.1200/jco.2016.34.15_suppl.3504

53. Venook AP, Ou F-S, Lenz H-J, et al (2017) Primary $\left(1^{\circ}\right)$ tumor location as an independent prognostic marker from molecular features for overall survival (OS) in patients (pts) with metastatic colorectal cancer (mCRC): Analysis of CALGB / SWOG 80405 (Alliance). J Clin Oncol 35:3503-3503. https://doi.org/10.1200/jco.2017.35.15_suppl.3503

54. Von Einem JC, Heinemann V, Von Weikersthal LF, et al (2014) Left-sided primary tumors are associated with favorable prognosis in patients with KRAS codon 12/13 wild-type metastatic colorectal cancer treated with cetuximab plus chemotherapy: An analysis of the AIO KRK-0104 trial. J Cancer Res Clin Oncol 140:1607-1614. https://doi.org/10.1007/s00432-014-1678-3

55. Weiss JM, Pfau PR, O'Connor ES, et al (2011) Mortality by stage for right- versus left-sided colon cancer: Analysis of surveillance, epidemiology, and end results-medicare data. J Clin Oncol 29:44014409. https://doi.org/10.1200/JC0.2011.36.4414 
56. Welch HG, Schwartz LM, Woloshin S (2000) Are increasing 5-year survival rates evidence of success against cancer? J Am Med Assoc 283:2975-2978. https://doi.org/10.1001/jama.283.22.2975

57. Winawer SJ, Zauber AG, Ho MN, et al (1993) Prevention of Colorectal Cancer by Colonoscopic Polypectomy. N Engl J Med 329:1977-1981. https://doi.org/10.1056/nejm199312303292701

58. Yamauchi M, Lochhead P, Morikawa T, et al (2012a) Colorectal cancer: A tale of two sides or a continuum? Gut 61:794-797

59. Yamauchi M, Morikawa T, Kuchiba A, et al (2012b) Assessment of colorectal cancer molecular features along bowel subsites challenges the conception of distinct dichotomy of proximal versus distal colorectum. Gut 61:847-854. https://doi.org/10.1136/gutjnl-2011-300865

60. Zhang Y, Ma J, Zhang S, et al (2015) A prognostic analysis of 895 cases of stage III colon cancer in different colon subsites. Int J Colorectal Dis 30:1173-1183. https://doi.org/10.1007/s00384-0152273-z

\section{Table}

Table 1: Characteristics of colorectal cancer cases

\begin{tabular}{|c|c|c|c|c|}
\hline & \multicolumn{2}{|c|}{ Incidence data-set } & \multicolumn{2}{|c|}{$\begin{array}{c}\text { Mortality data } \\
\text { set }\end{array}$} \\
\hline & $\mathrm{n}$ & $\%$ & $\mathrm{n}$ & $\%$ \\
\hline Total & 168,260 & 100 & 87,355 & 100 \\
\hline Localzation available & 136,604 & 81.2 & & \\
\hline colon cancer & 81,007 & 59.3 & 18,528 & 39.9 \\
\hline rectum cancer & 55,597 & 40.7 & 27,892 & 60.1 \\
\hline PTL available & 136,604 & 81.2 & 46,420 & 53.1 \\
\hline left sided primary & 100,204 & 73.4 & 40,087 & 86.4 \\
\hline right sided primary & 36,400 & 26.6 & 6,333 & 13.6 \\
\hline $\begin{array}{l}\text { Stage at diagnosis } \\
\text { available }\end{array}$ & 134,425 & 79.9 & 60,678 & 69.5 \\
\hline locoregional disease & 104,086 & 77.4 & 36,498 & 60.2 \\
\hline metastasized disease & 30,339 & 22.6 & 24,180 & 39.8 \\
\hline Gender & & & 87,355 & 100 \\
\hline female & 79,331 & 47.1 & 43,031 & 49.3 \\
\hline male & 88,929 & 52.9 & 44,324 & 50.7 \\
\hline
\end{tabular}

PTL primary tumor location

\section{Figures}




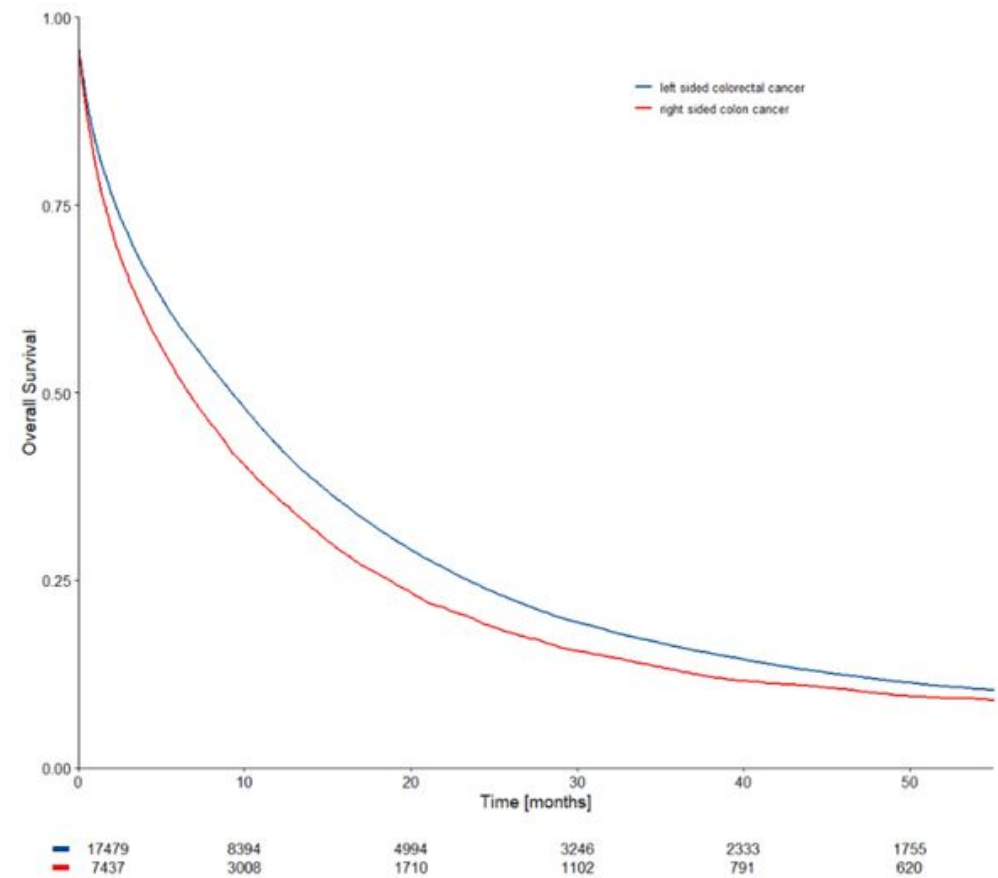

B

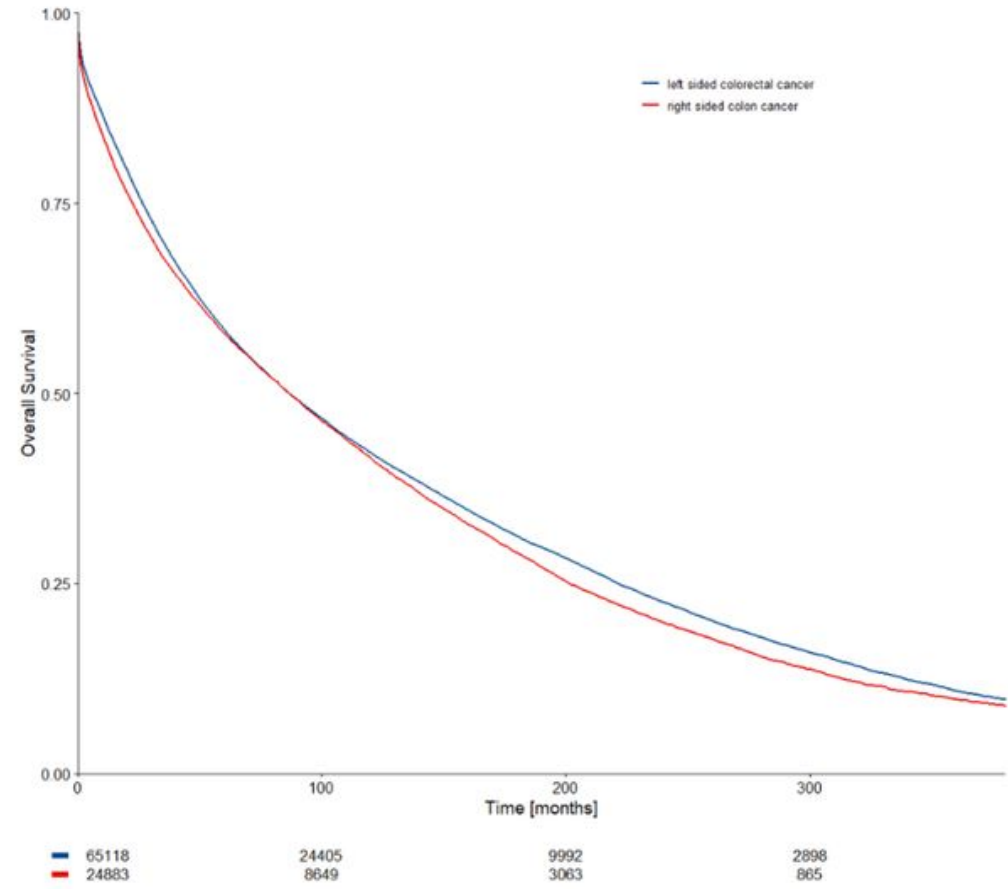

Figure 1

Overall survival of patients according to primary tumor location. (A) disseminated (metastatic) disease and (B) non-disseminated disease. 


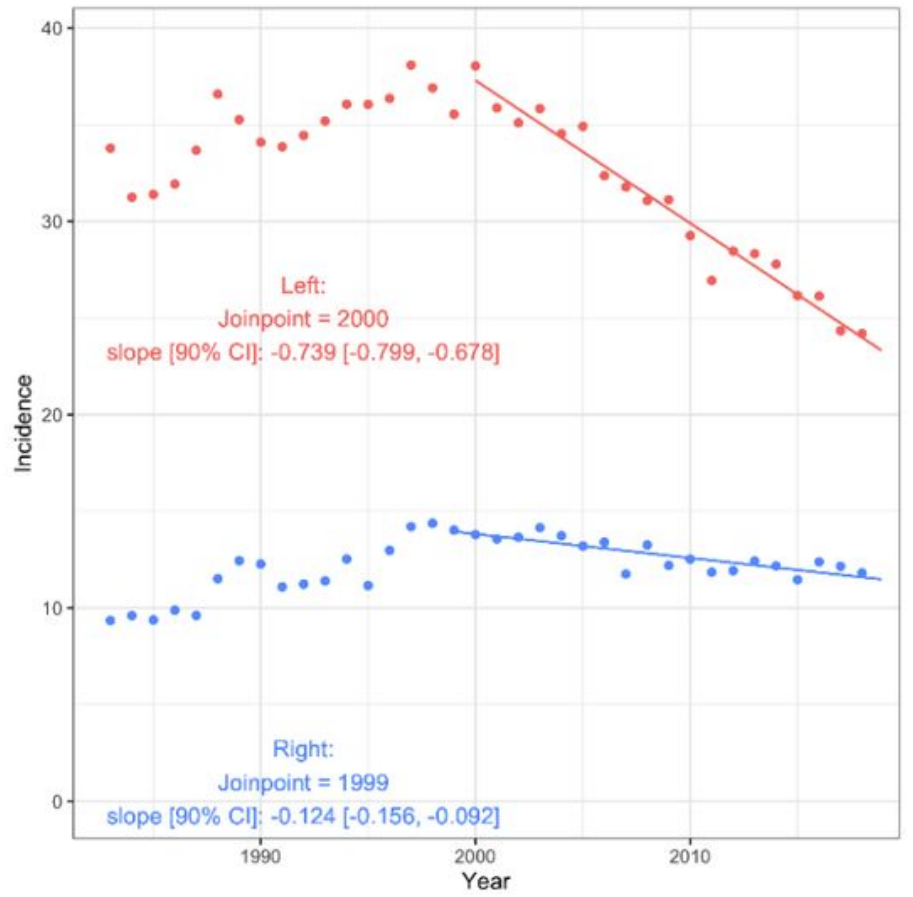

B

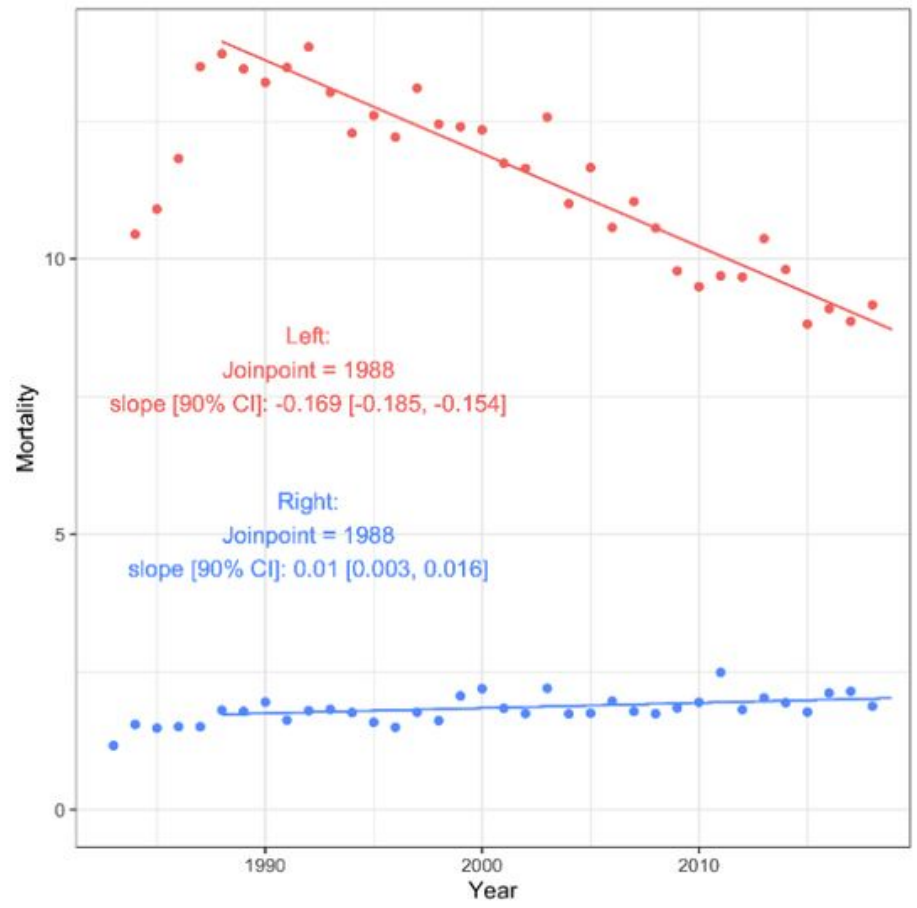

Figure 2

Standardized annual incidence- and mortality rates over time according to the primary tumor location. (A) Incidence rates in left and right sided CRC and (B) mortality rates in left- and right sided CRC 
A

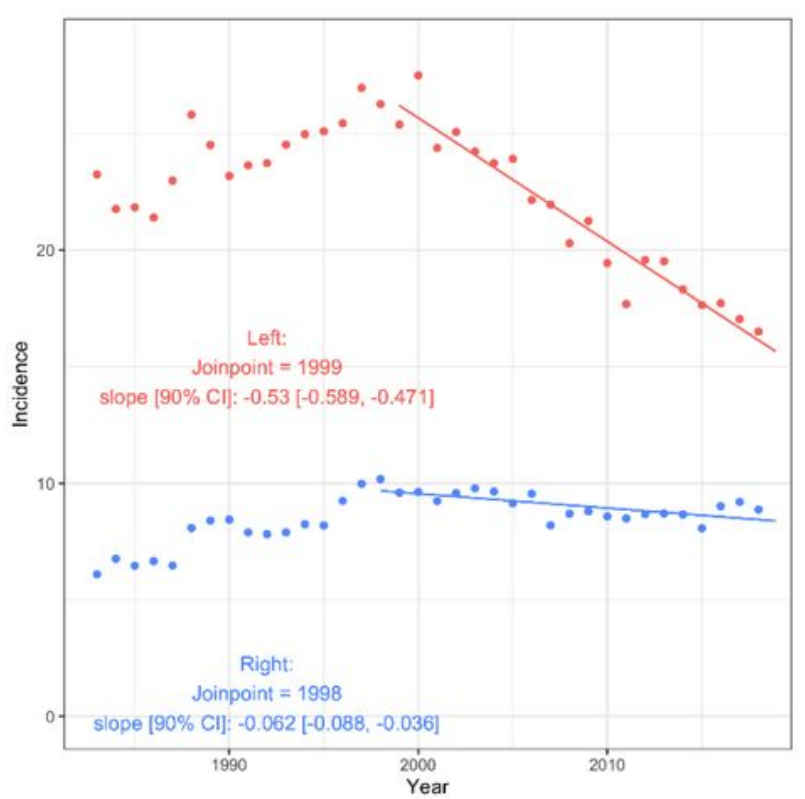

C

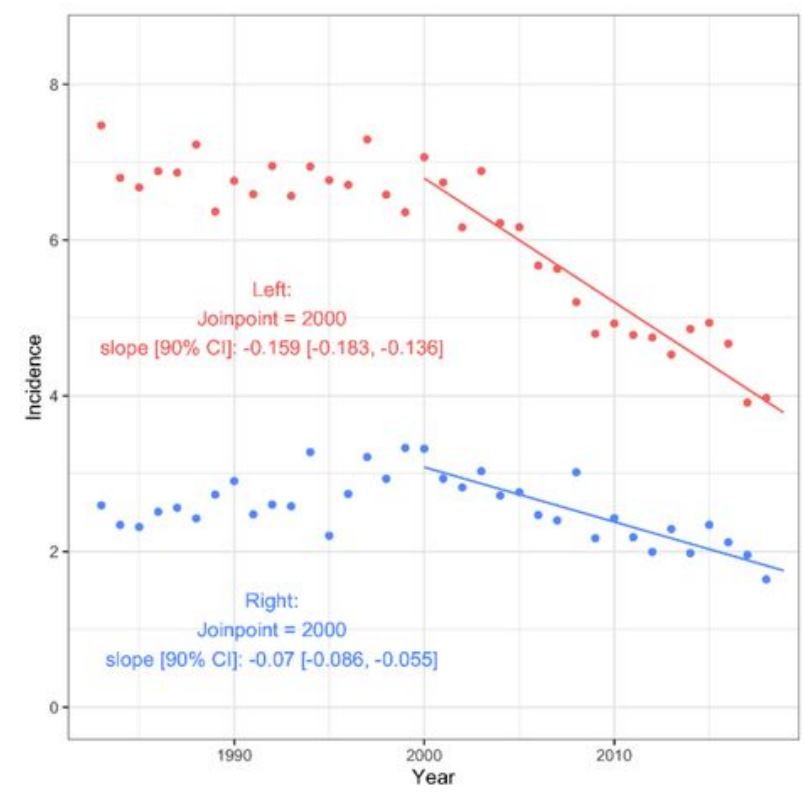

B

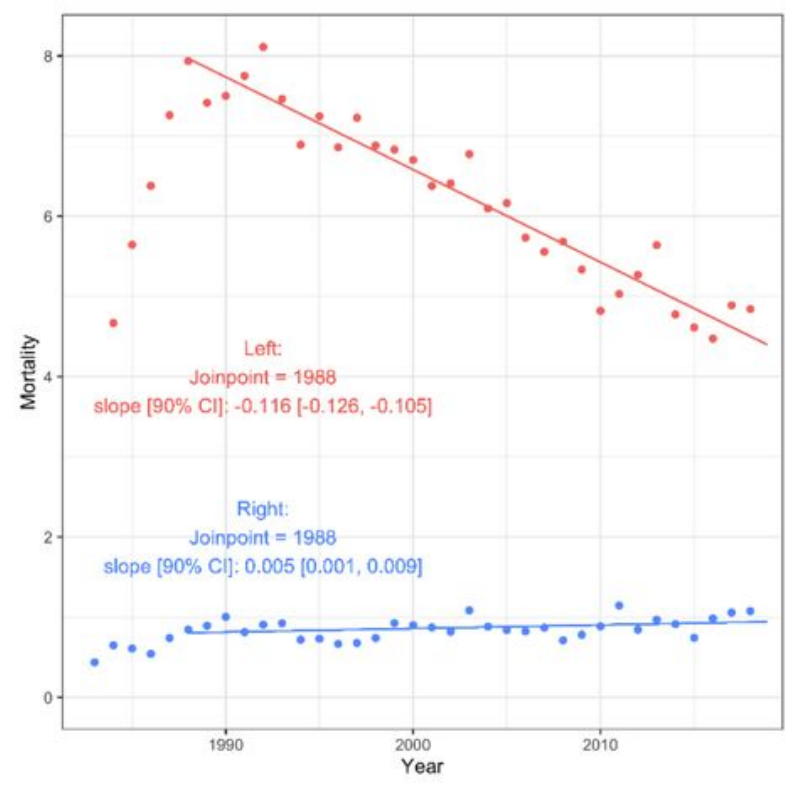

D

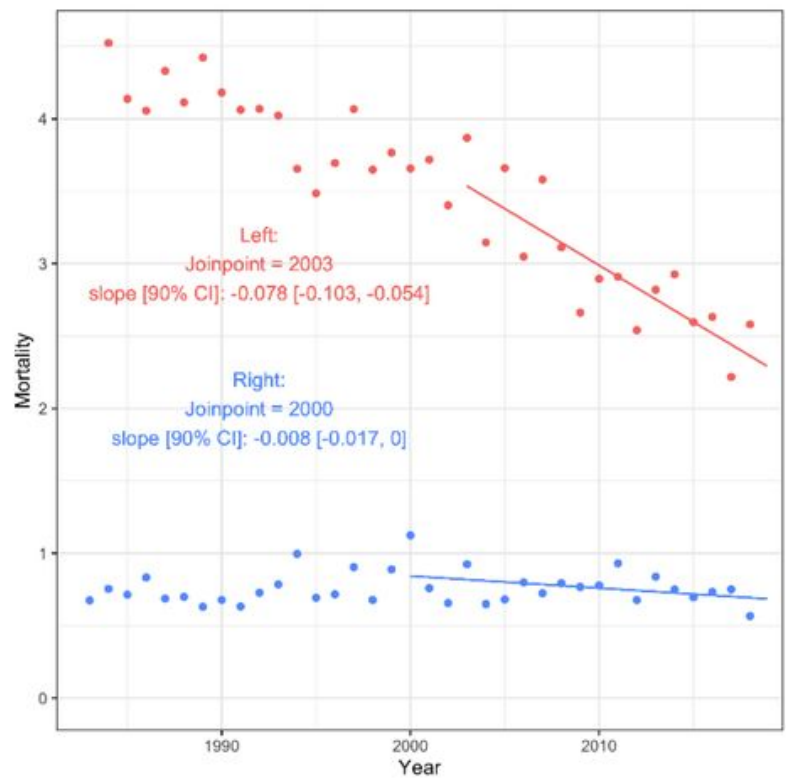

\section{Figure 3}

Standardized annual incidence- and mortality rates over time according to primary tumor location and stage. Incidence rates in (A) non-disseminated- and (C) disseminated disease; mortality rates according to primary tumor location according to primary tumor location in (B) non-disseminated and (D) disseminated disease. 